\title{
An intercomparison of antenna measurements made at a spherical near-field range, a cylindrical near-field range and a compact range
}

\section{Lemanczyk, J.; Larsen, Flemming Holm}

Published in:

Antennas and Propagation Society International Symposium

Publication date:

1984

Document Version

Publisher's PDF, also known as Version of record

Link back to DTU Orbit

Citation (APA):

Lemanczyk, J., \& Larsen, F. H. (1984). An intercomparison of antenna measurements made at a spherical nearfield range, a cylindrical near-field range and a compact range. In Antennas and Propagation Society International Symposium (Vol. Volume 22, pp. 686-689). IEEE.

\section{General rights}

Copyright and moral rights for the publications made accessible in the public portal are retained by the authors and/or other copyright owners and it is a condition of accessing publications that users recognise and abide by the legal requirements associated with these rights.

- Users may download and print one copy of any publication from the public portal for the purpose of private study or research.

- You may not further distribute the material or use it for any profit-making activity or commercial gain

- You may freely distribute the URL identifying the publication in the public portal 
AN INTERCOMPARISON OF ANTENNA MEASUREMENTS MADE AT A SPHERICAL NEAR-FIEID RANGE, A CYLINDRICAL NEAR-FIELD RANGE AND A COMPACT RANGE.

J. Hau Lemanczyk, F. Holm Larsen

Electromagnetics Institute, The Technical University of Denmark

Introduction. It still can occur at presentations of far-field results from near-field antenna measurements that the question is raised how well they compare to real far-field measurements. Experience has shown that usually it is not possible to carry out far-field measurements sufficiently accurate to demonstrate the full accuracy of the near-field measurements. Instead one can measure for different values of the parameters in the near-field measurement configuration, e.g. the measurement distance, and observe how sensitive the far-field patterns are to such changes [1]. However, in order to obtain a more convincing comparison, the European Space Agency has arranged for measurements of a contoured beam antenna at three different near-field measurement systems in three different countries. The three measurement facilities are

1. The spherical near-field scanner at the Technical University of Denmark.

2. The cylindrical near-field scanner at MBB in Munich, Germany.

3. The compact range at Technical University, Eindhoven, The Netherlands.

The antenna was an off-set reflector antenna with a contoured beam produced by a linear array of four feed horns perpendicular to the off-set plane. Before the measurements were started, the feed support structure was enforced to prevent movement during the measurements. Also a mirror cube was attached to the antenna in order to define a coordinate system for the antenna and a reference direction for the definition of co- and cross- polarization in particular. An extensive series of measurements were carried out at the spherical range at TUD as described in a separate paper to this conference [1].

Comparison spherical-cylindrical. The comparison between far-field patterns from spherical [1] and cylindrical [2] measurements is shown in figure 1 for the two principal planes of the antenna. The cross-polar field has in both measurements been determined perpendicular to a side face on the mirror cube. Careful alignment of the near-field scanners, the probe polarization reference and the test antenna is essential for obtaining the indicated agreement.

Comparison spherical scanner - compact range. A similar comparison between the far-field patterns from the spherical near-field measurements and measurements carried out at a compact range consisting of two cylindrical reflectors $[3,4]$ is shown in figure 2. Note that the angular scale has been changed relative to figure 1 . Also the cross-polar patterns are changed relative to figure 1 because the polarization of the feed horn in the compact range was aligned

$\mathrm{CH} 2043-8 / 84 / 0000-0686 \$ 01.00$ C) 1984 IEEE 
to produce a null close to $\theta=0^{\circ}$ rather than perpendicular to a cube face. Since both amplitude and phase of the two field components are known from the spherical near-field measurements it is possible to rotate the polarization reference in the computer and by rotating $3.83^{\circ}$, the agreement in figure $2 \mathrm{a}$ is obtained. The same reference angle is used for the spherical measurements in the $\hat{\phi}=90^{\circ}$ cut, while the feed horn in the compact range has been aligned separately for this cut. The fact that the cross - polar values are not the same for $\theta=0^{\circ}$ indicates some misalignment of the compact range. Table 1 gives some specific numbers for the comparison.

\begin{tabular}{|c|c|c|c|}
\hline & TUD & MBB & THE \\
\hline lobe $(\theta, \phi)=\left(5.1^{\circ}, 0^{\circ}\right)$ & -0.19 & -0.19 & -0.13 \\
\hline side lobe $(\theta, \phi)=\left(7.6^{\circ}, 90^{\circ}\right)$ & -20.2 & -20.6 & -22.2 \\
\hline cross-polar max $\phi=0^{\circ}$ plane & $\begin{array}{l}-20.8 \\
-17.0\end{array}$ & -21.5 & -17.2 \\
\hline
\end{tabular}

Table 1. Comparison of specific values in aB relative to co-polar max.

\section{References}

[1] J. Hau Lemanczyk, J.E. Hansen, F.H. Larsen, "Evaluation of the spherical near field range at the Technical University of Denmark". Paper submitted to the 1984 International IEEE/AP-S Symposium, Boston.

[2] C.P. Fischer, "Cylinarical near field test facility for large satellite antennas". 13th European Microwave Conference, Nürnberg, West Germany, 1983.

[3] V.J. Vokurka, "Compact antenna range", Ch. 9.3 in Satellite Communication Technology, Mittra, Imbriale and Maanders editors, North Holland, Amsterdam, 1983.

[4] M.H.M. Knoben, "Compact antenna range measurements on the MBB four horn offset antenna". Dept. of Electrical Engineering, Eindhoven University of Technology, Report ET-3-83.

This work was carried out under work package WP2 of a rider to ESA Contract $4682 / 81 / \mathrm{NL} / \mathrm{NS}$ (SC). 


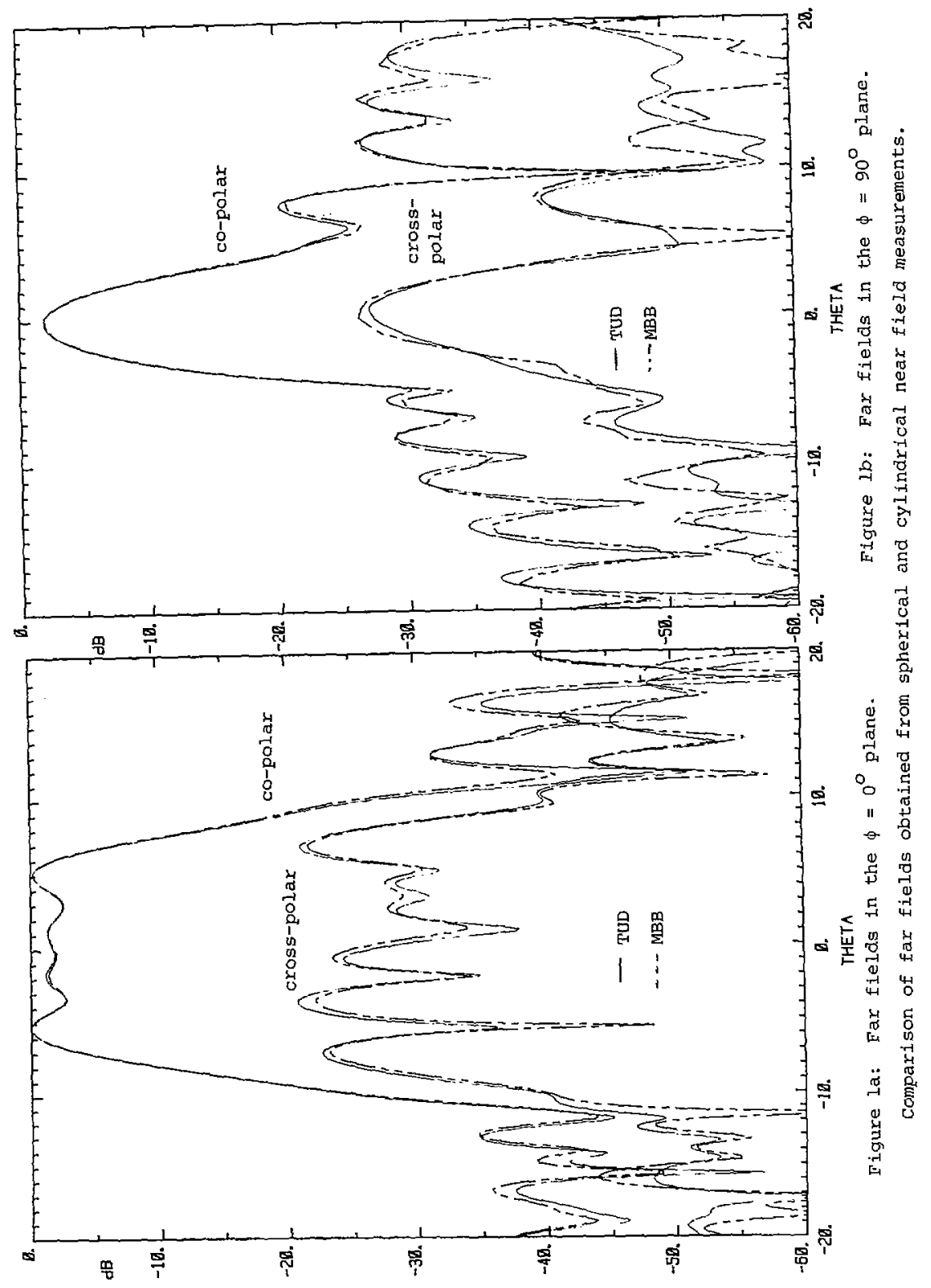




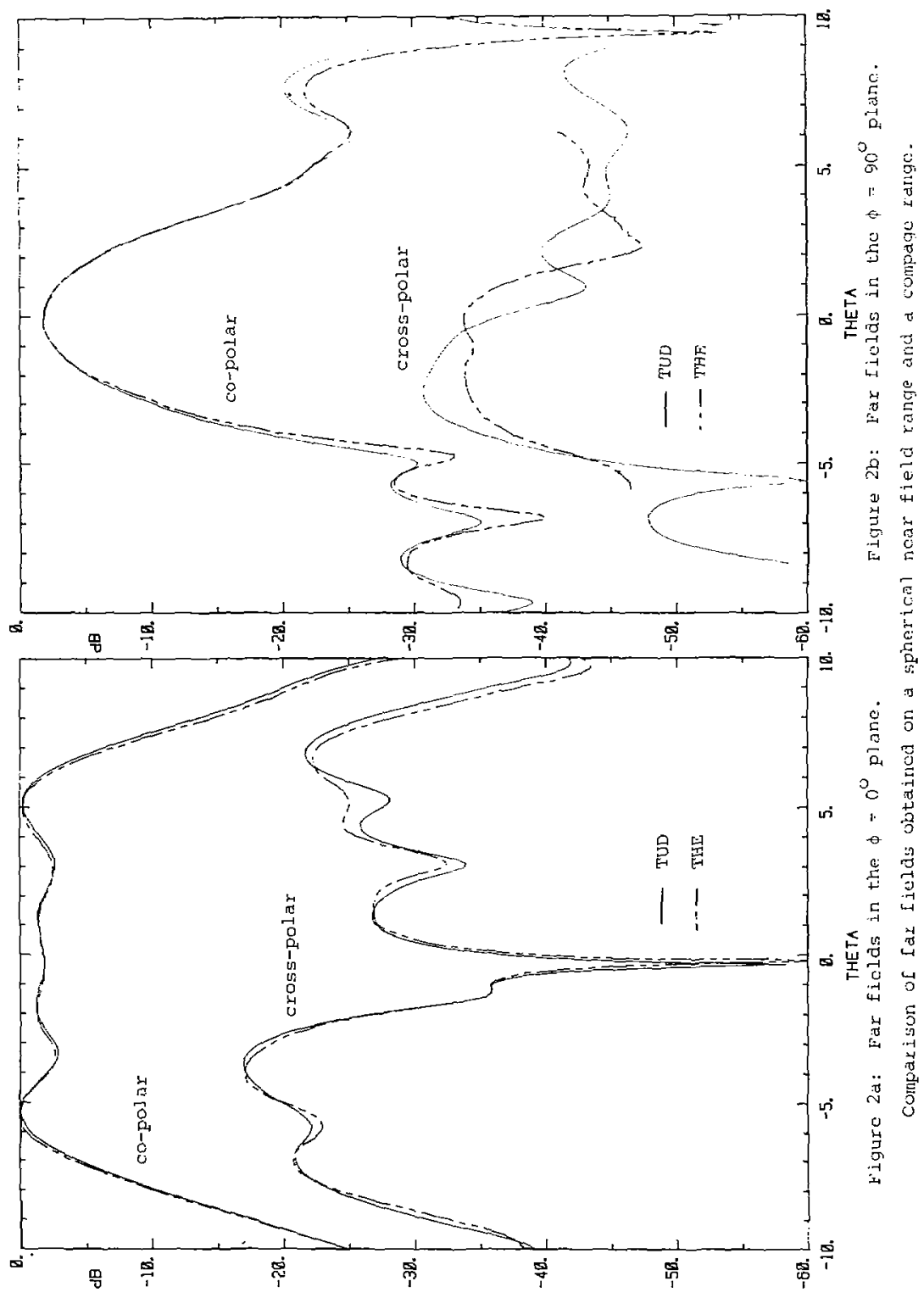

sed use limited to: Danmarks Tekniske Informationscenter. Downloaded on July 01,2010 at 07:52:49 UTC from IEEE Xplore. Res 